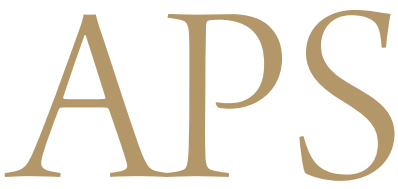

Archives of Plastic Surgery

\title{
Our Experiences in Nipple Reconstruction Using the Hammond flap
}

\author{
Jung Dug Yang, Jeong Yeop Ryu, Dong Wan Ryu, O Hyun Kwon, Sung Gun Bae, \\ Jeong Woo Lee, Kang Young Choi, Ho Yun Chung, Byung Chae Cho \\ Department of Plastic and Reconstructive Surgery, Kyungpook National University School of Medicine, Daegu, Korea
}

Background Nipple reconstruction following breast mound reconstruction is the final step in breast reconstruction. Although nipple reconstruction is a simple surgery, the psychological aspects of nipple reconstruction are thought to be important. Nipple projection is a key factor in determining patient satisfaction with the surgery. In the present study, the Hammond flap technique was introduced for nipple reconstruction.

Methods Twenty-six patients who had undergone breast reconstruction from February 2008 to March 2012 were enrolled in this prospective study. All patients were evaluated based on preoperative photos, and their nipple diameters and heights were measured. Postoperative evaluation was conducted $3,6,9$, and 12 months following nipple reconstruction. A questionnaire on patient satisfaction with the nipple reconstruction was administered 12 months after nipple reconstruction. Moreover, the same plastic surgeon scored nipple projection and overall cosmetic result of the new nipple.

Results The mean projection was $4.4 \mathrm{~mm}$ (range, 3-6 mm), and it well matched the contralateral nipple. Twelve months following nipple reconstruction, the mean reduction rate in the nipple projection was $43.6 \%$. Patients were satisfied or very satisfied with the nipple projection and the overall cosmetic result in $80.7 \%$ cases.

Conclusions In the present study, compared with other techniques, the use of the Hammond flap technique in nipple reconstruction showed competitive results with regard to nipple projection and patient satisfaction.

Keywords Nipples / Surgery / Plastic / Mammaplasty
Correspondence: Jung Dug Yang Department of Plastic and Reconstructive Surgery, Kyungpook National University School of Medicine, 130 Dongdeok-ro, Jung-gu, Daegu 700-421, Korea

Tel: $+82-53-420-5688$

Fax: +82-53-425-3879

E-mail: lambyang@daum.net

No potential conflict of interest relevant to this article was reported.

\section{INTRODUCTION}

The frequency of breast reconstruction has recently increased owing to an increase in the number of breast cancer cases. Breast cancer patients awaiting mastectomy experience tremendous stress from the moment they are diagnosed with breast cancer to the impending mastectomy and accompanying physiological changes [1]. Accordingly, breast reconstruction should attempt to reverse mastectomy-induced physiological changes as close to the preoperative state as possible. Nipple reconstruction is the final step in breast reconstruction after mastectomy.

Although nipple reconstruction is a simpler procedure than breast reconstruction, the psychological aspect of nipple reconstruction plays an important role in breast reconstruction. Previous studies have shown that patient satisfaction with breast reconstruction outcomes varies greatly with the presence or ab- 
sence of the nipple [2]. Therefore, successful nipple reconstruction leads to higher patient satisfaction levels because it is indicative of complete restoration of the breast to its original state before mastectomy. However, complications of nipple reconstruction include loss of nipple projection, loss of sensation in the breast, and abnormal placement of the nipple. Among these, loss of nipple projection correlates closely with low levels of satisfaction [3]. As such, it is important to minimize the loss of nipple projection during the nipple reconstruction procedure.

Nipple reconstruction was first introduced in 1944 by Adams [4] by using the nipple areola graft method and has continued to progress with the development of various surgical methods. Recently, nipple reconstruction using various local flap techniques has become popular and is recognized as the standard procedure in nipple reconstruction. Various local flap techniques such as the S-flap, skate flap, double opposing tab flap, propeller flap, $\mathrm{H}$-flap, star flap, and C-V flap have been introduced [5]. In 2007, Shestak and Nguyen [6] and Hammond et al. [7] each introduced the double opposing peri-areolar flap/ skate flap purse-string design as a method of nipple reconstruction by modifying the original skate flap technique. This double opposing peri-areolar/purse-string flap is commonly called the Hammond flap (Fig. 1). Thereafter, the effectiveness of the
Hammond flap was confirmed by Dolmans et al. [8] and Katsuragi et al. [9] and the authors have used Hammond flaps in numerous cases of nipple reconstruction. Here, we aimed to determine the benefits of using the Hammond flap in nipple reconstruction by analyzing objective measurements and subjective patient satisfaction levels.

\section{METHODS}

\section{Subjects}

Twenty-six patients, who had undergone breast reconstruction from February 2008 to March 2012, were enrolled in this prospective study. The same surgical staff who had performed breast reconstruction by using the autologous extended latissimus dorsi flap performed nipple reconstruction using the Hammond flap without any implant insertion. Patients with flap necrosis or surgical wound infection were excluded from the study.

\section{Surgical methodology}

The nipple-areola complex was designed with the patient in the upright position. The circle around the outside of the nippleareola complex formed the boundary line. In the rectangular design, the center of the horizontal line was used to determine the

\section{Fig. 1. Original and modified Hammond flap}

(A) Schematic view of the preoperative design of original Hammond flap. (B) Immediate postoperative view of the original Hammond flap. (C) Schematic design of the modified Hammond flap using a minimal skin incision. (D) Immediate postoperative view of the modified Hammond flap using minimal skin incision. $R_{1}$ flap radius: $D$, areola diameter; $C$, new nipple cap; $P$, new nipple projection.

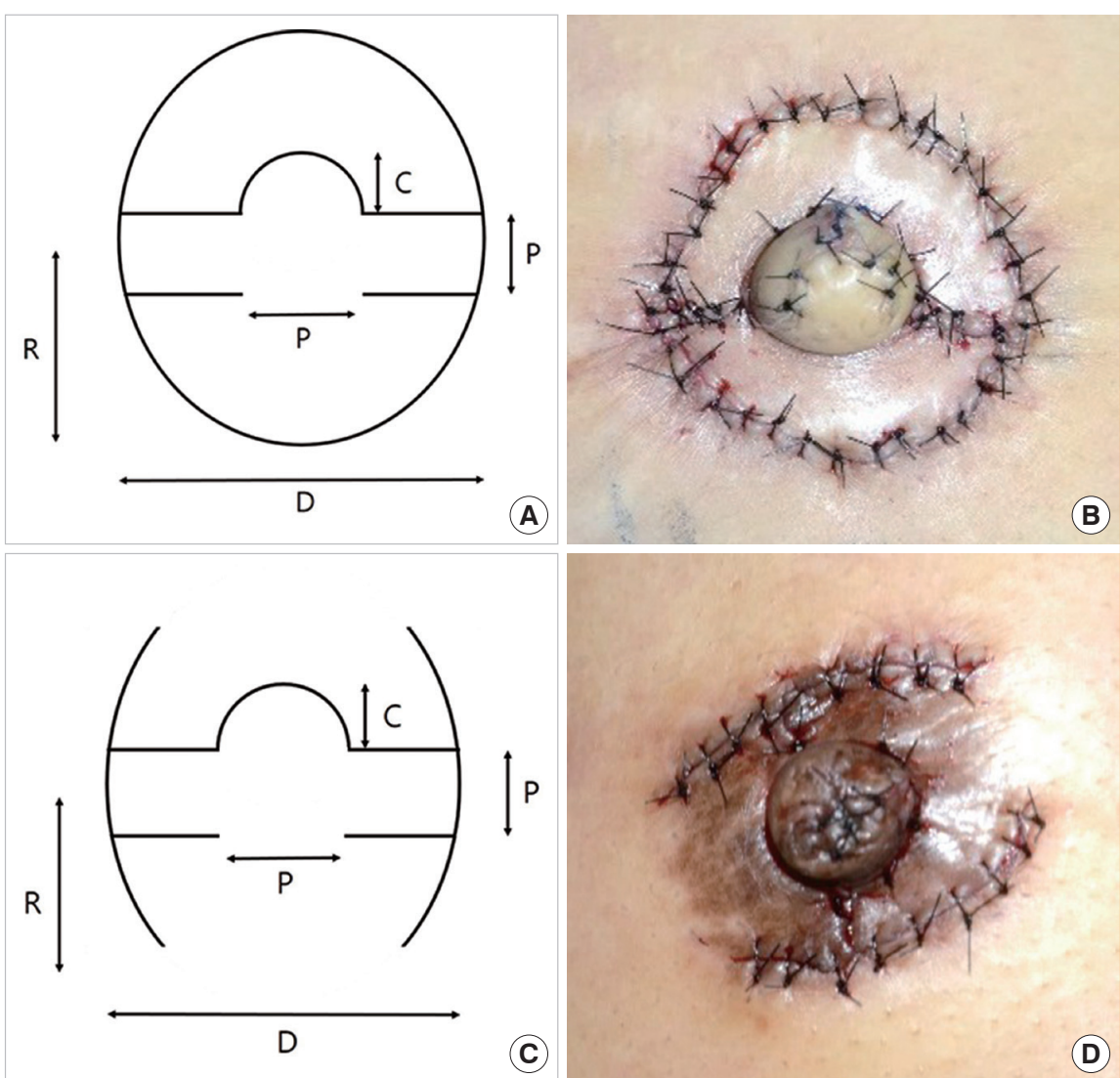


base of the nipple during the reconstruction, while the vertical length was used to determine the height of the nipple-the nipple projection (Fig. 1). The base of the flap was positioned halfway between the center and lower border of the new nipple. After designing the nipple-areola complex, $2 \%$ lidocaine was used to induce local anesthesia. Without damaging the flap pedicle, an incision was then made using a scalpel blade (\#15) following the incision line. The incision enabled movement of the threedimensional structure of the new nipple flap, allowing it to be erect. The outer wings of the skate flap were elevated by dissection, which included a small amount of subdermal fat. The base and wings of the skate flap was elevated with an even layer of subdermal fat. Finally, the approximation of the donor flapthat would later form the areola-was performed. Because excessive tension in the donor flap can have a negative effect on the nipple projection, efforts were taken to minimize the tension in the donor flap while proceeding with the purse-string suture.

\section{Measurement}

All study patients had photographs taken before and after the operation at 3, 6, 9, and 12 months. The nipple-areola complex was measured by the same medical staff, and the nipple diameter, nipple height, and areolar diameters of the affected nippleareola complex were measured at the 3-, 6-, 9-, and 12-month follow-up visits. The individual reduction rate of the nipple projection was calculated using the measured values. The reduction rate of the nipple projection was formulated as follows:

Rdeuction rate of the nipple projection $=$

$$
1-\frac{\text { Current nipple height }}{\text { Immediate postoperative nipple height }} \times 100(\%)
$$

\section{Satisfaction}

At the 12-month follow-up visit, study patients were asked to rate their satisfaction with the nipple reconstruction on a scale of 1-10. The survey provided information on the satisfaction levels with regard to the overall nipple reconstruction, projection, location, and sensation.

Table 1. Nipple projection reduction rate of the Hammond flap

\begin{tabular}{|lcc|}
\hline Follow-up & Nipple height $(\mathrm{mm})$ & Reduction rate (\%) \\
\hline Initial & $7.8 \pm 1.2$ & $\mathrm{~N} / \mathrm{A}$ \\
$3 \mathrm{mo}$ & $5.3 \pm 0.5$ & $31.4 \pm 5.3$ \\
6 mo & $4.8 \pm 0.4$ & $38.5 \pm 4.4$ \\
9 mo & $4.5 \pm 0.3$ & $41.8 \pm 4.1$ \\
$12 \mathrm{mo}$ & $4.4 \pm 0.3$ & $43.6 \pm 3.7$ \\
\hline N/A, not applicable. & & \\
\hline
\end{tabular}

\section{RESULTS}

A total of 26 patients were included in the study, with an average age of $47.9 \pm 7.8$ years. The reconstruction of the breast mound was performed using an extended latissimus dorsi flap, and nipple reconstruction was performed using a Hammond flap. There were no complications or flap revisions. The mean initial nipple height was $7.8 \pm 1.2 \mathrm{~mm}$. At the 12 -month follow-up, the mean nipple height was $4.4 \pm 0.3 \mathrm{~mm}$, and the average reduction rate of nipple projection was $43.6 \pm 3.7 \%$. The nipple height and reduction rates of nipple projection at 3-, 6-, 9-, and 12-month follow-ups are shown in Table 1 . At the 12-month follow-up, the overall patient satisfaction level was $80.7 \%$, and the satisfaction levels with regard to nipple projection, location, and sensation are as shown in Fig. 2.

\section{Case}

A 38-year-old woman had undergone breast mound reconstruction using an extended latissimus dorsi flap and nipple reconstruction with a Hammond flap. Nipple height was $8.7 \mathrm{~mm}$ immediately after the procedure. At the 3-, 6-, 9-, and 12-month follow-ups, the nipple height reached 7.6, 6.4, 5.2, and $4.7 \mathrm{~mm}$, respectively (Fig. 3).

\section{DISCUSSION}

The characteristics of a normal nipple include its texture and color, nipple projection, and fluid discharge function. These

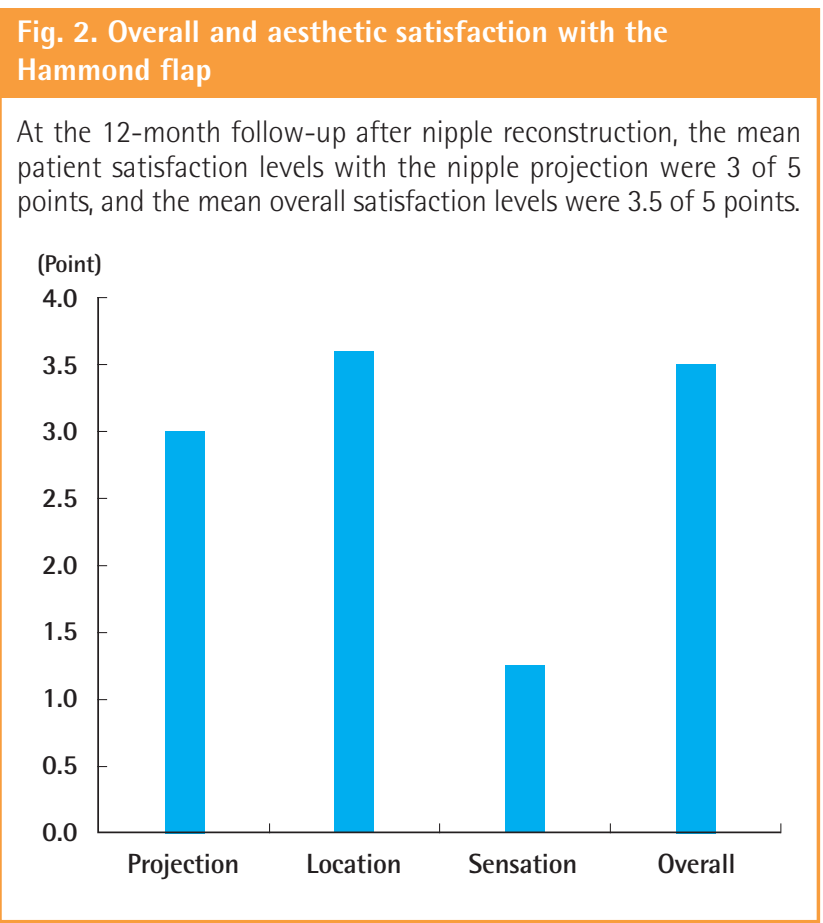




\section{Fig. 3. The Hammond flap: a case report}

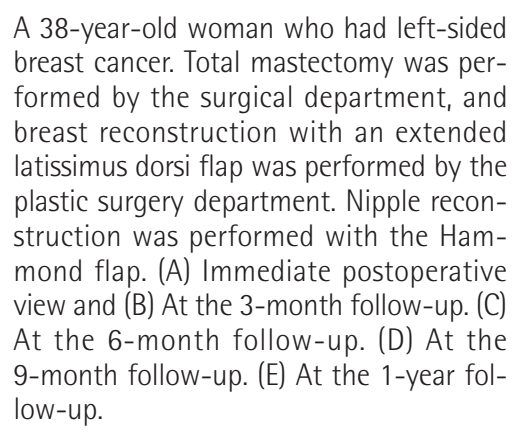

A 38-year-old woman who had left-sided breast cancer. Total mastectomy was performed by the surgical department, and breast reconstruction with an extended latissimus dorsi flap was performed by the plastic surgery department. Nipple reconstruction was performed with the Hammond flap. (A) Immediate postoperative view and (B) At the 3-month follow-up. (C) At the 6-month follow-up. (D) At the 9-month follow-up. (E) At the 1-year follow-up.
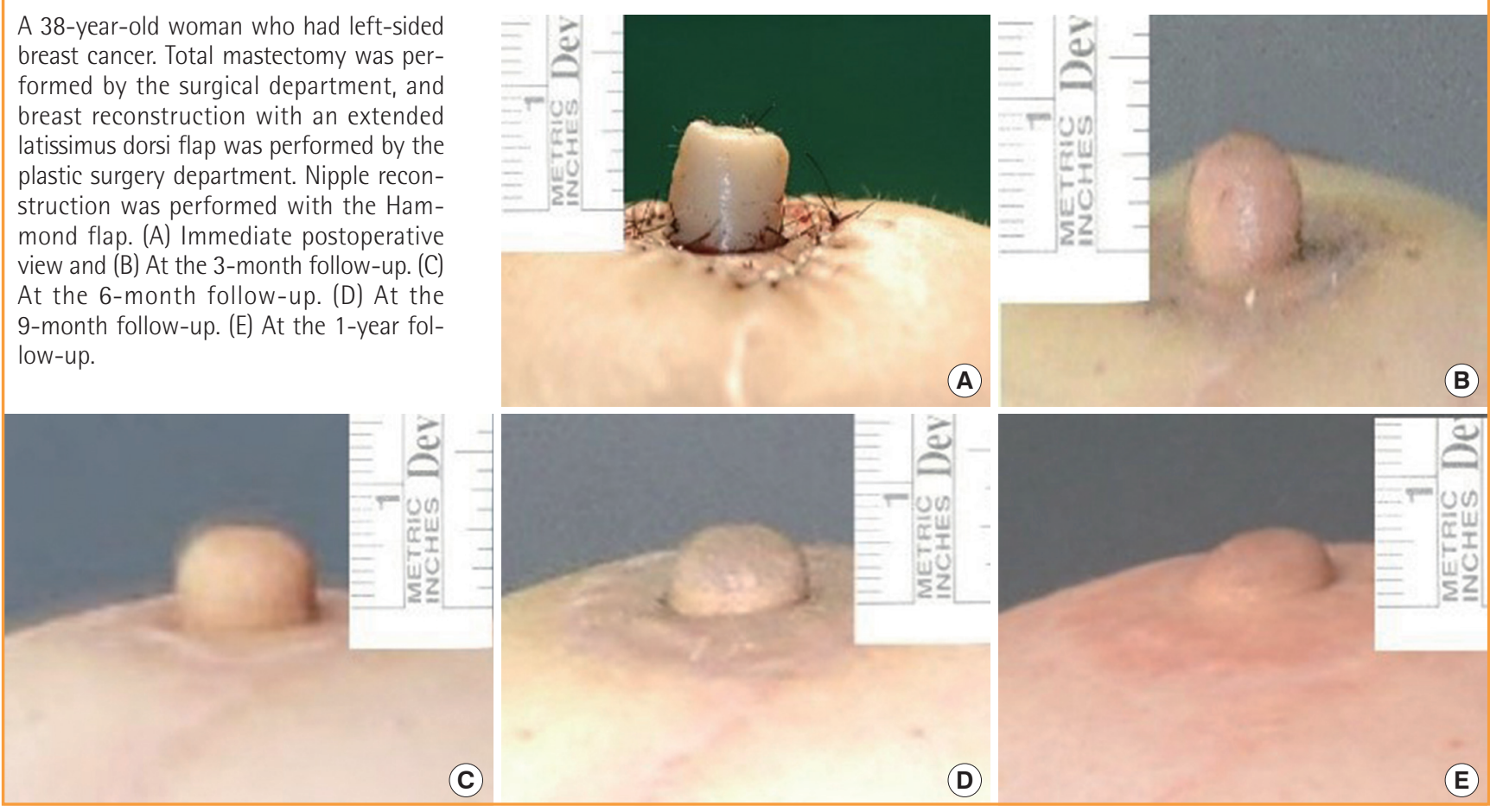

(A)

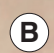

(C)

(D) characteristics must be considered prior to performing nipple reconstruction.

Generally, the average nipple is approximately $5 \mathrm{~mm}$ in height, and its ideal location is at the apex of the breast [10]. However, in effect, the location of the nipple after reconstruction is determined by the shape of the reconstructed breast mound. Normally, it is difficult to achieve symmetry owing to various differences in the reconstructed breast mound and the breast on the unaffected side. Therefore, it would be favorable to perform nipple reconstruction 6-8 months after breast mound reconstruction to allow the grafted flap to soften and the shape of the breast to set [11].

There are various nipple reconstruction methods, including the composite nipple graft, local flap, autologous implant graft, alloplastic implant augmentation, and allograft implant augmentation. However, the most common nipple reconstruction is via local flap surgery. In 2007, Shestak and Nguyen [6] invented and published the double opposing peri-areola flap for nipple areola reconstruction. It was reported that this pull-out nipple flap has been used 47 times with satisfactory results, causing no flap loss or wound separation. Simultaneously, Hammond et al. [7] announced a new surgical technique, the skate flap pursestring technique. This surgical technique was designed in consideration of the fact that using the skate-flap for nipple reconstruction yields better results in terms of nipple projection, and that this technique involves a combination of the modified skate flap and purse-string techniques during mastopexy. This technique was similar to the surgical technique published by Shestak and Nguyen [6] and has become widely known as the Hammond flap. The Hammond flap can produce large nipples, can allow primary closure of the donor site, and can minimize breast distortion. In addition, the blood supply to the nipple flap is derived primarily from the subdermal plexus, and this technique minimizes the need to cut the pedicle, thus securing a reliable blood supply. In patients undergoing skin-sparing mastectomy, the Hammond flap provides the advantage of hiding the surgical scar along the areolar margin.

Although various nipple reconstructions using local flap techniques have been introduced, commonly, the nipple projection reduces over time in all currently known local flap techniques. This reduction in nipple projection can be attributed to scar tissue retraction, soft tissue absorption, necrosis, compression from clothing, and nearby skin surface tension due to reconstruction [8]. To address this issue, new methods for maintaining nipple projection have been introduced, including over-correction of the new nipple and application of a device to maintain nipple protection after reconstruction [12,13]. Accordingly, in an attempt to maintain long-term the projection of the new nipple, we over-correct the nipple size by $30 \%$ to $50 \%$ during nipple reconstructions and use a nipple cap for flap preservation for a week after the procedure in order to promote wound healing. After suture removal, a nipple-areolar protection device (Ther- 
aShells, Medela Inc., McHenry, IL, USA) is applied for $>2$ months. The new areola was tattooed at least 2 months following nipple reconstruction, as tattooing can affect the loss of nipple projection.

In addition, blood circulation to the new nipple is an important factor in maintaining long-term nipple projection and acute flap wound care. Blood circulation to the new nipple after reconstruction with a local flap can be improved by 1) minimizing the skin incision; 2) avoiding a deep incision during the procedure to protect the subdermal plexus near the pedicle; and 3) avoiding narrowing of the base of the flap. Given that maximum blood supply improves wound healing, in a recent ongoing study, the authors designed an incision line-only one-third of the overall size — on both sides of the areola that maintained maximum blood supply to the areolar flap, while elevating the flap recently (Fig. 1). The modified flap has advantages and disadvantages over the original technique. The advantage of the modified flap is the possibility of improved blood circulation for the new nipple flap. Because the incision is minimized, the blood circulation can be improved. Furthermore, because of the incomplete incision, scarring following areolar incision can be reduced. The disadvantage of the modified flap is that it can produce a "dog-ear" after approximation of the 2 areolar flaps. Thus, the dog-ear should be removed for excellent cosmetic results. Among 26 patients in this study, the original Hammond flap was applied to 21 patients and the modified technique was performed to 5 patients. The authors could not find the differences in nipple height between the original and modified Hammond flap technique. Further studies will be needed to investigate these differences.

Several studies have reported long-term follow-up results with various local flap techniques. Rubino et al. [13] performed nipple reconstruction using the arrow flap technique on $32 \mathrm{pa}-$ tients. Among these, breast mound reconstruction using an implant was performed in 16 patients, and breast mound reconstruction using the transverse rectus abdominis myocutaneous flap technique was performed on the other 16 patients. At the 1 -year follow-up, the projection rate was reduced by $50.9 \%$. Few et al. [14] reported a 59\% reduction in the projection rate at the 8 -year follow-up in patients who had undergone the modified star flap technique. Valdatta et al. [15] reported a $42 \%$ reduction in the projection rate at the 1-year follow-up in patients who had undergone breast reconstruction with silicone implants for breast mound reconstruction, using the C-V flap. Overall, the reported nipple projection reduction is in the range of approximately $40 \%$ to $60 \%$ (Table 2 ). The present study shows slightly better results than the aforementioned studies. It is possible that such results were obtained because patients in this study had undergone breast mound reconstruction using the autologous extended latissimus dorsi flap with its thick skin envelope, and the Hammond flap allowed sufficient blood supply and minimized tension in the new nipple flap. Losken et al. [16] reported that patient satisfaction levels at an average follow-up of 5.3 years was $42 \%$ with the nipple projection and $81 \%$ with the overall nipple reconstruction performed by using the C-V flap [16]. At the 1-year follow-up, Jones and Erdmann [17] reported a 57\% satisfaction level with the nipple projection and $91 \%$ satisfaction level with the overall nipple reconstruction performed by using the Hamburger flap. In the study published by Lipa et al. [18], a fishtail flap and cartilage graft were simultaneously performed, and an overall satisfaction score of 7.6 out of 10 was reported after 3.7 years of follow-up. The satisfaction levels with

Table 2. Comparison of the nipple projection reduction rates in our study and those in other studies

\begin{tabular}{|lclllcc}
\hline Study & Patient no. & Technique & \multicolumn{1}{c}{ Mound } & P (mm) & RR (\%) & Follow-up (yr) \\
\hline Rubino et al. [13] & 32 & Arrow flap & Implant 16, TRAM flap 16 & 4.75 & 50.9 & 1 \\
Few et al. [14] & 93 & Modified star flap & Implant 44, TRAM flap 49 & $0.4-0.83$ & 59 & 8 \\
Valdatta et al. [15] & 29 & C-V flap & Implant & 3.52 & 42 & 1 \\
Our study & 26 & Hammond flap & Extended LD flap & 4.4 & 43.6 & 1 \\
\hline P, projection; RR, reduction rate; TRAM, transverse rectus abdominis myocutaneous; LD, latissimus dorsi. & & & \\
\hline
\end{tabular}

Table 3. Patient satisfaction levels in our study compared with those in previous studies

\begin{tabular}{|lllllccc}
\hline Study & \multicolumn{1}{c}{ Technique } & Mound & Pr/S & Ov/S & Pr/R (\%) & Ov/R (\%) & Follow-up (yr) \\
\hline Losken et al. [16] & C-V flap & TRAM flap & N/A & N/A & 42 & 81 & 5.3 \\
Jones and Erdmann [17] & Hamburger flap & N/A & N/A & N/A & 57 & 91 & 1 \\
Lipa et al. [18] & Fishtail flap+cartilage & Autologous flap & N/A & $7.6 / 10$ & N/A & N/A & 3.7 \\
Our study & Hammond flap & Extended LD flap & $3 / 5$ & $3.5 / 5$ & - & 80.7 & 1 \\
\hline $\begin{array}{l}\text { Pr/S, projection score; Ov/S, overall score; Pr/R, satisfaction rate of projection; Ov/R, overall satisfaction rate; TRAM, transverse rectus abdominis myocutaneous; N/A, not } \\
\text { applicable; LD, latissimus dorsi. }\end{array}$ & & & &
\end{tabular}


the nipple projection and overall process are $40 \%$ to $50 \%$ and $80 \%$ to $90 \%$, respectively. The present study shows results similar to those of other studies (Table 3).

As previously stated, nipple reconstruction using the Hammond flap offers several advantages, including resultant large nipples, primary closure at the donor site, minimal breast distortion, and reliable blood supply. In addition, the Hammond flap is a surgical procedure with similar-or even superior-longterm projection results relative to other techniques previously reported. Furthermore, patient satisfaction levels with the Hammond flap are higher than those with other techniques; thus, it is useful in nipple reconstruction.

\section{REFERENCES}

1. Wilkins EG, Cederna PS, Lowery JC, et al. Prospective analysis of psychosocial outcomes in breast reconstruction: oneyear postoperative results from the Michigan Breast Reconstruction Outcome Study. Plast Reconstr Surg 2000;106: 1014-25.

2. Wellisch DK, Schain WS, Noone RB, et al. The psychological contribution of nipple addition in breast reconstruction. Plast Reconstr Surg 1987;80:699-704.

3. Little JW. Nipple-areolar reconstruction. In: Cohen M, editor. Mastery of plastic and reconstructive surgery. Boston: Little, Brown; 1994. p.1342-8.

4. Adams WM. Free transplantation of the nipples and areola. Surgery 1944;15:186-9.

5. Ketan MP, Maurice YN. Reconstruction of the nipple-areola complex. In: Neligan P, editor. Plastic surgery. 3rd ed. New York: Elsevier Saunders; 2013. p.488-520.

6. Shestak KC, Nguyen TD. The double opposing periareola flap: a novel concept for nipple-areola reconstruction. Plast Reconstr Surg 2007;119:473-80.

7. Hammond DC, Khuthaila D, Kim J. The skate flap pursestring technique for nipple-areola complex reconstruction.
Plast Reconstr Surg 2007;120:399-406.

8. Dolmans GH, van de Kar AL, van Rappard JH, et al. Nipple reconstruction: the "Hammond" flap. Plast Reconstr Surg 2008;121:353-4.

9. Katsuragi Y, Kayano S, Koizumi T, et al. How long does the nipple projection last after reconstruction using the skate flap purse-string technique? Plast Reconstr Surg 2011;127: 149e-51e.

10. Mathes SJ, Hentz VR. Plastic surgery. 2nd ed. Philadelphia: Saunders Elsevier; 2006.

11. Kim DY, Dhong ES, Yoon ES, et al. Long-term result of nipple reconstruction using skate flap after breast reconstruction. J Korean Soc Plast Reconstr Surg 2011;38:401-7.

12. Sircar T, Chouhan A, Johri A. Cartella eye-shield as a dressing after nipple reconstruction - a technical innovation. Ann R Coll Surg Engl 2010;92:439-40.

13. Rubino C, Dessy LA, Posadinu A. A modified technique for nipple reconstruction: the 'arrow flap'. Br J Plast Surg 2003; 56:247-51.

14. Few JW, Marcus JR, Casas LA, et al. Long-term predictable nipple projection following reconstruction. Plast Reconstr Surg 1999;104:1321-4.

15. Valdatta L, Montemurro P, Tamborini F, et al. Our experience of nipple reconstruction using the C-V flap technique: 1 year evaluation. J Plast Reconstr Aesthet Surg 2009;62: 1293-8.

16. Losken A, Mackay GJ, Bostwick J 3rd. Nipple reconstruction using the $\mathrm{C}-\mathrm{V}$ flap technique: a long-term evaluation. Plast Reconstr Surg 2001;108:361-9.

17. Jones AP, Erdmann M. Projection and patient satisfaction using the "Hamburger" nipple reconstruction technique. J Plast Reconstr Aesthet Surg 2012;65:207-12.

18. Lipa JE, Addison PD, Neligan PC. Patient satisfaction following nipple reconstruction incorporating autologous costal cartilage. Can J Plast Surg 2008;16:85-8. 